\title{
Tumour necrosis factor gene polymorphisms and migraine in Greek children
}

Styliani Pappa, Maria Hatzistilianou, Anastasia Kouvatsi, Chrysa Pantzartzi, Afroditi Sakellaropoulou, Evangelos Pavlou, Ioannis Mavromichales, Fanni Athanassiadou

School of Medicine, Aristotle University, Thessaloniki, Greece

Submitted: 16 August 2009

Accepted: 3 October 2009

Arch Med Sci 2010; 6, 3: 430-437

DOI: 10.5114/aoms.2010.14267

Copyright @ 2010 Termedia \& Banach
Corresponding author:

Prof. Maria Hatzistilianou

School of Medicine

Aristotle University

Agiou loannou 23

Kalamaria 55132

Thessaloniki, Greece

E-mail: nontas@topo.auth.gr

\begin{abstract}
Introduction: Migraine is considered to be a multifactorial, complex disease. Various genetic and environmental factors contribute to the manifestation of this disease. The aim of this study was to determine whether polymorphisms in the tumour necrosis factor (TNF) region are associated with the risk of migraine. We examined the association between 6 single nucleotide polymorphisms in the coding regions of TNF- $\alpha$ and TNF- $\beta$ genes and migraine. Material and methods: The study included two groups of children (group A and group B). Group A consisted of 103 unrelated children with typical migraine without aura 5-14 years of age. Group B (control group) consisted of 178 unrelated healthy children. The diagnosis of migraine was, in all patients, made according to the International Classification of Headache Disorders (ICHD II). Results: According to our results positive family history was present in $62.2 \%$ of patients of group A. No significant differences were found in the frequencies of genotypes or alleles between patients and controls. The non-parametric analyses of variance showed no significant differences in the age at onset between genotype groups of the TNF- $\alpha$ and TNF- $\beta$ gene polymorphisms. Comparison of genotype frequencies between boys and girls in affected patients and control individuals were not significantly different $(p=0.089, p=0.073$ respectively). The distribution of TNF polymorphisms was not associated with the presence of family history of migraine in patients.

Conclusions: Our data indicate that TNF- $\alpha$ and TNF- $\beta$ gene polymorphisms are not a significant risk factor for migraine without aura in Greek children.
\end{abstract}

Key words: migraine, tumour necrosis factor $\alpha$, tumour necrosis factor $\beta$, polymorphism, children.

\section{Introduction}

Migraine is a multifactorial, complex disease. The aetiology of a migraine attack is only partly understood [1]. It is considered that various genetic and environmental factors contribute to the manifestation of this disease $[2,3]$. The mode of transmission of migraine in families is still unclear since migraine does not fit a simple Mendelian pattern.

The type and the number of genes which link to migraine are still unclear [4]. An increased knowledge of the genetic risk factors as well as an understanding of the underlying pathogenesis is expected to enable clinicians to identify children at a high risk and to treat childhood migraine more effectively [4]. 
Many of the genetic factors, such as the TNF gene, the calcium channel gene CACNAIA, and the ednra gene, which have to date been shown to be linked to adult migraine susceptibility have also been investigated in children $[5,6]$. Polymorphisms in several candidate genes have been proposed either as susceptibility markers or as useful tools for the dissection of the related phenotypes [5-7]. The pathophysiology of migraine is still unknown, although "sterile inflammation" or "neurogenic inflammation" seems to play a key role [8].

Tumour necrosis factor (TNF) is a cytokine implicated in inflammatory reactions and endothelial function. There is considerable evidence for a major role of TNF in initiating inflammatory hyperalgesia [10-12].

Tumour necrosis factor can promote powerful hyperalgesia by causing prostanoid release, increasing the expression of bradykinin receptors or by modulation of activity within sympathetic fibres. Increased levels of TNF- $\alpha$ in migraineurs have been documented; therefore, it may be involved in migraine [13]. Also, TNF- $\alpha$ is a possible pain mediator in neurovascular inflammation. Therefore it might be a potential mechanism for the generation of migraine pain. Rainero et al. [14] have reported that homozygosity for the $G$ allele in TNF- $\alpha-308$ was associated with an increased risk of migraine in an Italian population. However, previous studies concerning the role of TNF- $\alpha$ in migraine have provided conflicting results and there has been no confirmation of the role of TNF- $\alpha-308$ markers in migraine patients [10, 14-16].

The aim of this study was to determine whether polymorphisms in the TNF region are associated with the risk of migraine. Therefore we examined the association between 6 single nucleotide polymorphisms in the coding regions of TNF- $\alpha$ and TNF- $\beta$ genes and migraine in Greek children.

\section{Material and methods}

The study included two groups of children (group A and group B). Group A consisted of 103 unrelated children with typical migraine without aura 5 -14 years of age (mean age $\pm \mathrm{SE}=10.5 \pm 0.7$ ), 46 boys (44.7\%) and 57 girls (55.3\%). All children of group A were attending the paediatric headache outpatient clinic of the $2^{\text {nd }}$ Department of Paediatrics of the Medical School of Aristotle University of Thessaloniki. The diagnosis of migraine was, in all patients, made according to the International Classification of Headache Disorders (ICHD II) by a neurologist specialized in paediatric headaches, while a family history concerning the presence of migraine attacks in parents and siblings was obtained from the parents themselves, through an interview by specialized personnel [17]. The patient underwent an extensive physical and neurological examination. Positive family history was present in $82 \%$ of patients of group $A$.

Group B (control group) consisted of 178 unrelated healthy children, 75 boys (42.1\%) and 103 girls $(57.9 \%)$, the age range (mean age \pm SE $=12.2 \pm 1.7$ ). The healthy children (used as controls) consisted of individuals whose parents were interviewed and indicated in a questionnaire that they had never suffered from migraine or any similar condition and that the same was true of their first and second degree relatives. Patients and controls originated from the same geographical region (northern Greece) and were recruited in parallel, at a similar time and geographical location as the case group, to avoid the potential bias of population stratification. The mean age of the control group was, in an attempt to exclude subjects with late-onset migraine, purposely higher than the age of the patients. Written informed consent was obtained from all parents of the participants. This research was approved by the Local Ethics Committee.

\section{Genetic analysis}

Genomic DNA was isolated from whole peripheral blood according to the protocol of the manufacturer (Pure gene, DNA purification system, Gentra). The analysis of DNA samples was performed by the PCR-RFLPs method. Six single nucleotide polymorphisms (SNPs) in TNF genes (TNF- $\alpha-238$ G/A, TNF- $\alpha-308 \mathrm{G} / \mathrm{A}$, TNF- $\alpha-1031 \mathrm{~T} / \mathrm{C}$, TNF- $\alpha-857 C /$ T, TNF- $\alpha-376 G / A$, and TNF- $\beta-252$ A/G) were genotyped by the $P C R$ restriction fragment length polymorphism (RFLP) method.

\section{Genotyping}

The forward primer sequence and the reverse sequence of all 6 SNPS are shown in Table I. In Table II are shown the restriction enzyme, the PCR product and digest fragment (bp) after the action of the restriction enzyme of all 6 polymorphisms.

\section{Statistical analysis}

Hardy-Weinberg equilibrium (HWE) of alleles at individual loci and comparison of genotype frequencies between cases and controls were assessed by $\chi^{2}$ statistics.

Estimation of allele frequencies and haplotypes was performed with the Gene Hunter program. Genotypes were tested for HWE using the exact test. The significance of differences in the allele and genotype frequencies between the groups was determined by the $\chi^{2}$ test. One way analysis of variance performed via the Mann-Whitney test was used to evaluate the possible influence of TNF polymorphisms on the age at onset. The samples 
Table I. Primer sequences of all TNF polymorphisms

\begin{tabular}{|c|c|c|c|}
\hline SNPs & Primer name & & Primers \\
\hline \multirow{2}{*}{$\begin{array}{l}\text { TNF- } \alpha \text { : } \\
-238 G / A\end{array}$} & TNF_238F & $\mathrm{F}$ & 5'-AGAAGACCCCCCTCGGAACC-3' \\
\hline & TNF_238_376R & $\mathrm{R}$ & 5'-GCTGGTCCTCTGCTGTCCTTG-3' \\
\hline \multirow{2}{*}{$\begin{array}{l}\text { TNF- } \alpha: \\
-308 G / A\end{array}$} & TNF- $\alpha-308 F$ & $\mathrm{~F}$ & 5'-AGGCAATAGGTTTTGAGGGCCAT-3' \\
\hline & TNF- $\alpha-308 R$ & $\mathrm{R}$ & 5'-TCCTCCCTGCTCCGATTCCG-3' \\
\hline \multirow{2}{*}{$\begin{array}{l}\text { TNF- } \alpha: \\
-376 A / G\end{array}$} & TNF_376F & $\mathrm{F}$ & 5'-CAACCCCGTTTTCTCTCCCTC-3' \\
\hline & TNF_238_376R & $\mathrm{R}$ & 5'-GCTGGTCCTCTGCTGTCCTTG-3' \\
\hline \multirow{2}{*}{$\begin{array}{l}\text { TNF- } \alpha: \\
-857 C / T\end{array}$} & TNF_1031_857_F & $\mathrm{F}$ & 5'-CAGGGGAAGCAAAGGAGAAG-3' \\
\hline & TNF_1031_857_R & $\mathrm{R}$ & 5'-CCCTCTACATGGCCCTGTCTAC-3' \\
\hline \multirow{2}{*}{$\begin{array}{l}\text { TNF- } \alpha: \\
-1031 T / C\end{array}$} & TNF_1031_857_F & $\mathrm{F}$ & 5'-CAGGGGAAGCAAAGGAGAAG-3' \\
\hline & TNF_1031_857_R & $\mathrm{R}$ & 5'-CCCTCTACATGGCCCTGTCTAC-3' \\
\hline \multirow{2}{*}{ TNF- $\beta$} & TNF-B_F & $\mathrm{F}$ & 5'-GGTTTCCTTCTCTGTCTCTGACTCTCC-3' \\
\hline & TNF-B_R & $R$ & 5'-GAGAGAGATCGACAGAGAAGGGGAC-3' \\
\hline
\end{tabular}

Table II. The restriction enzyme, the PCR product and digest fragment (bp) after the action of the restriction enzyme of all 6 polymorphisms

\begin{tabular}{|lcccc|}
\hline SNPs & Restriction enzyme & PCR product [bp] & \multicolumn{2}{c|}{ Restriction enzyme digest fragment [bp] } \\
\cline { 3 - 5 } & & & Normal & Mutant \\
\hline TNF- $\alpha:-238 \mathrm{G} / \mathrm{A}$ & $\mathrm{Mspl}$ & 299 & $280 \pm 19$ & 299 \\
\hline TNF- $\alpha:-308 \mathrm{G} / \mathrm{A}$ & $\mathrm{Ncol}$ & 107 & $87 \pm 20$ & 107 \\
\hline TNF- $\alpha:-376 \mathrm{~A} / \mathrm{G}$ & $\mathrm{Tsp509I}$ & 504 & 504 & $418 \pm 86$ \\
\hline TNF- $\alpha:-857 \mathrm{C} / \mathrm{T}$ & $\mathrm{HpyCH}_{4}$ IV & 226 & $203 \pm 23$ & 226 \\
\hline TNF- $\alpha:-1031 \mathrm{C} / \mathrm{C}$ & $\mathrm{Bbsl}$ & 226 & 226 & $194 \pm 32$ \\
\hline TNF- $\beta$ & $\mathrm{Ncol}$ & 173 & $102 \pm 71$ & 173 \\
\hline
\end{tabular}

were stratified for genotypes at each locus. Statistical analyses were performed using the Statistical Package for the Social Sciences (SPSS, version 11.0). Value of $p<0.05$ was considered significant.

\section{Results}

In control and case populations, at the polymorphic loci considered, the genotype counts were in Hardy-Weinberg equilibrium, with nonsignificant $\chi^{2}$ values. The genotype distribution and allele frequencies of TNF gene polymorphisms are shown in Table III. No significant differences were found in the frequency of the genotype or allele between patients and controls.

We assessed pairwise linkage disequilibrium (LD) among SNPs in control subjects and we observed strong LD among the polymorphisms TNF-857 and TNF-1031, TNF-857 and TNF- $\alpha-308$, TNF-857 and TNF- $\beta$, TNF-1031 and TNF- $\beta$, TNF- $\alpha-308$ and TNF- $\beta$, TNF-1031 and TNF-238, TNF-376 and TNF-238 $\left(r^{2}=0.1-0.28, D^{\prime}=0.84-1\right.$, Table IV).

The genotypes for the TNF resulted in five possible haplotypes, the frequencies of which are given in Table V. The haplotype distribution did not differ between group A and group B. Further haplotype analysis therefore did not give any additional information to the analysis of the individual SNPS. (The likelihood ratio test (LRT) for the haplotype-phenotype association is not statistically significant $\left[\chi^{2}=0.72, \mathrm{~d} f=4, p=0.949\right]$ ).

The non-parametric analyses of variance performed via Mann-Whitney test showed no significant differences in the age at onset between genotype groups and the six polymorphisms (Table VI).

Comparison of genotype frequencies between boys and girls in affected patients and control individuals were not significantly different (Table VII).

The presence of family history of migraine in patients is shown in Figure 1. The distribution of TNF polymorphisms was not associated with the presence of family history of migraine in patients (Table VIII).

\section{Discussion}

Our study demonstrates no significant differences in the genotype distributions and allele frequencies of TNF gene polymorphisms between 
Table III. Genotype distribution and allele frequencies of TNF gene polymorphisms in groups A and B

\begin{tabular}{|c|c|c|c|c|c|}
\hline \multirow[t]{3}{*}{ TNF } & \multicolumn{2}{|c|}{ Genotypes } & \multicolumn{3}{|c|}{ Alleles } \\
\hline & Group A & Group B & & Group A & Group B \\
\hline & $n(\%)$ & $n(\%)$ & & $n(\%)$ & $n(\%)$ \\
\hline \multicolumn{6}{|c|}{ TNF- $\alpha-238$} \\
\hline GG & $96(93.2)$ & $170(95.5)$ & All 1 (G) & $199(96.6)$ & $348(97.8)$ \\
\hline GA & $7(6.8)$ & $8(4.5)$ & All 2 (A) & $7(3.4)$ & $8(2.2)$ \\
\hline AA & & & \multicolumn{3}{|c|}{$p=0.419$} \\
\hline \multicolumn{6}{|c|}{$\begin{array}{c}p=0.546 \operatorname{Exp}(B)=0.707 \\
95 \% \mathrm{Cl} 0.230-2.180\end{array}$} \\
\hline \multicolumn{6}{|c|}{ TNF- $\alpha-308$} \\
\hline GG & $89(86.4)$ & $145(81.5)$ & All 1 (G) & $192(93.2)$ & $321(90.2)$ \\
\hline GA & $14(13.6)$ & $31(17.4)$ & All $2(A)$ & $14(6.8)$ & $35(9.8)$ \\
\hline AA & $0(0)$ & $2(1.1)$ & \multicolumn{3}{|c|}{$p=0.281$} \\
\hline \multicolumn{6}{|c|}{$\begin{array}{c}p=0.370 \operatorname{Exp}(\mathrm{B})=1.388 \\
95 \% \mathrm{Cl} 0.678-2.840\end{array}$} \\
\hline \multicolumn{6}{|c|}{ TNF- $\alpha-376$} \\
\hline GG & $102(99)$ & $178(100)$ & All 1 (G) & $205(99.5)$ & $356(100)$ \\
\hline GA & $1(1)$ & $0(0)$ & All $2(A)$ & $1(0.5)$ & \\
\hline AA & & & & $p=0$. & \\
\hline \multicolumn{6}{|c|}{$p=1.000 \operatorname{Exp}(\mathrm{B})=0.000$} \\
\hline \multicolumn{6}{|c|}{ TNF- $\alpha-857$} \\
\hline CC & $64(62.1)$ & $113(63.5)$ & All 1 (C) & $159(77.2)$ & $280(78.7)$ \\
\hline CT & $31(30.1)$ & $54(30.3)$ & All $2(\mathrm{~T})$ & $47(22.8)$ & $76(21.3)$ \\
\hline \multirow[t]{2}{*}{ TT } & $8(7.8)$ & $11(6.2)$ & \multicolumn{3}{|c|}{$p=0.754$} \\
\hline & \multicolumn{2}{|c|}{$\begin{array}{c}p=0.758 \operatorname{Exp}(B)=1.091 \\
95 \% \mathrm{Cl} 0.627-1.900\end{array}$} & & & \\
\hline \multicolumn{6}{|c|}{ TNF- $\alpha-1031$} \\
\hline $\mathrm{TT}$ & $66(64.1)$ & $110(61.8)$ & All $1(\mathrm{~T})$ & $165(80.1)$ & $284(79.8)$ \\
\hline TC & $33(32)$ & $64(36)$ & All 2 (C) & 41 (19.9) & $72(20.2)$ \\
\hline $\mathrm{CC}$ & $4(3.9)$ & $4(2.2)$ & & $p=1$. & \\
\hline \multicolumn{6}{|c|}{$\begin{array}{c}p=0.560 \operatorname{Exp}(\mathrm{B})=1.180 \\
95 \% \mathrm{Cl} 0.677-2.057\end{array}$} \\
\hline \multicolumn{6}{|c|}{ TNF- $\beta$} \\
\hline GG & $4(3.9)$ & $10(5.6)$ & All 1 (G) & 39 (18.9) & 77 (21.6) \\
\hline GA & $31(30.1)$ & $57(32)$ & All 2 (A) & $167(81.1)$ & $279(78.4)$ \\
\hline $\mathrm{AA}$ & $68(66)$ & $111(62.4)$ & & $p=0$. & \\
\hline \multicolumn{3}{|c|}{$\begin{array}{c}p=0.640 \operatorname{Exp}(\mathrm{B})=0.741 \\
95 \% \mathrm{Cl} 0.211-2.603\end{array}$} & & & \\
\hline
\end{tabular}

patients with migraine without aura and healthy controls. We report for the first time the distributions of TNF alleles and genotypes in Greek children affected by migraine without aura. Also, we report for the first time the molecular analysis of TNF- $\alpha-238$, TNF- $\alpha-376$, TNF- $\alpha-857$ and TNF- $\alpha-1031$ alleles in children affected by migraine.
Previous studies concerning the role of TNF gene polymorphisms in migraine have provided conflicting results and there has been no confirmation of the role of TNF gene polymorphisms as markers in migraine patients $[10,14,16]$.

Our data for TNF-308G/A are in accordance with the results of Trabace et al., as well as Asuni et al. 
S. Pappa, M. Hatzistilianou, A. Kouvatsi, C. Pantzartzi, A. Sakellaropoulou, E. Pavlou, I. Mavromichales, F. Athanassiadou

Table IV. Linkage disequilibrium coefficients ( $\mathrm{D}^{\prime} \mid$ and $\left.\left|r^{2}\right|\right)$ among TNF polymorphisms

\begin{tabular}{|lcccccc|}
\hline & TNF-238 & TNF-308 & TNF-376 & TNF-857 & TNF-1031 & TNFB \\
\hline TNF-238 & 1 & 1.00 & 0.02 & 1.00 & 0.95 & 1.00 \\
\hline TNF-308 & 0.00 & 1 & 0.11 & 1.00 & 0.59 & 0.84 \\
\hline TNF-376 & 0.00 & 0.00 & 1 & 0.27 & 0.25 & 0.28 \\
\hline TNF-857 & 0.01 & 0.03 & 0.00 & 1 & 0.91 & 1.00 \\
\hline TNF-1031 & 0.08 & 0.01 & 0.00 & 0.06 & 1 & 1.00 \\
\hline TNF- $\alpha$ & 0.01 & 0.28 & 0.00 & 0.07 & 0.07 & 1 \\
\hline
\end{tabular}

Table V. Association between different TNF haplotypes and migraine

\begin{tabular}{|c|c|c|c|c|c|c|c|c|c|c|}
\hline \multirow{2}{*}{ 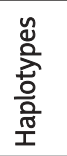 } & \multirow{2}{*}{ 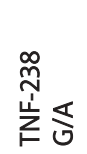 } & \multirow{2}{*}{ 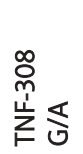 } & \multirow{2}{*}{ 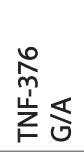 } & \multirow{2}{*}{$\begin{array}{l}\hat{n} \\
0 \\
\dot{1} \\
\sum \\
⺊\end{array}$} & \multirow{2}{*}{ 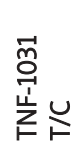 } & \multirow{2}{*}{ 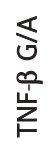 } & \multicolumn{2}{|c|}{ Frequencies } & \multirow{2}{*}{ OR $(95 \% \mathrm{Cl})$} & \multirow[t]{2}{*}{ Value of $p$} \\
\hline & & & & & & & Group A & Group B & & \\
\hline $\mathrm{Ht} 1$ & G & G & G & C & T & $A$ & 0.371 & 0.367 & & \\
\hline $\mathrm{Ht} 2$ & G & G & G & $T$ & $T$ & $A$ & 0.222 & 0.209 & $1.041(0.658-1.645)$ & 0.864 \\
\hline $\mathrm{Ht} 3$ & G & G & G & C & C & $A$ & 0.177 & 0.168 & $1.054(0.626-1.776)$ & 0.843 \\
\hline $\mathrm{Ht} 4$ & G & G & G & C & $T$ & G & 0.126 & 0.130 & $0.965(0.550-1.691)$ & 0.900 \\
\hline $\mathrm{Ht} 5$ & G & A & G & C & $T$ & $G$ & 0.068 & 0.086 & $0.776(0.370-1.627)$ & 0.502 \\
\hline
\end{tabular}

Table VI. Correlation between genotypes and the age of onset of the disease

\begin{tabular}{|c|c|c|}
\hline SNPs & Genotypes & Age of onset of disease (group A) \\
\hline \multirow[t]{3}{*}{ TNF-238 } & GG & $9.10 \pm 0.318$ \\
\hline & GA & $10.00 \pm 1.528$ \\
\hline & & $p=0.463$ \\
\hline \multirow[t]{3}{*}{ TNF-308 } & GG & $9.31 \pm 0.342$ \\
\hline & $G A+A A$ & $8.33 \pm 0.667$ \\
\hline & & $p=0.278$ \\
\hline \multirow[t]{2}{*}{ TNF-376 } & GG & $9.17 \pm 0.318$ \\
\hline & GA & \\
\hline \multirow[t]{3}{*}{ TNF-857 } & $\mathrm{CC}$ & $9.08 \pm 0.392$ \\
\hline & $\mathrm{CT}+\mathrm{TT}$ & $9.31 \pm 0.522$ \\
\hline & & $p=0.748$ \\
\hline \multirow[t]{3}{*}{ TNF-1031 } & TT & $9.44 \pm 0.375$ \\
\hline & $\mathrm{TC}+\mathrm{CC}$ & $8.67 \pm 0.540$ \\
\hline & & $p=0.234$ \\
\hline \multirow[t]{2}{*}{ TNF- $\beta$} & GG & \\
\hline & $G A+A A$ & $9.15 \pm 0.317$ \\
\hline
\end{tabular}

$[10,12]$, but the same data are in discordance with those of Rainero et al. and Mazaheri et al. $[14,16]$. These two recent studies showed an increased risk of migraine without aura associated with the TNF- $\alpha$ G308A polymorphism (Table IX).

Our data for TNF- $\beta$ are in discordance with those of Trabace et al., as well as Asuni et al., and

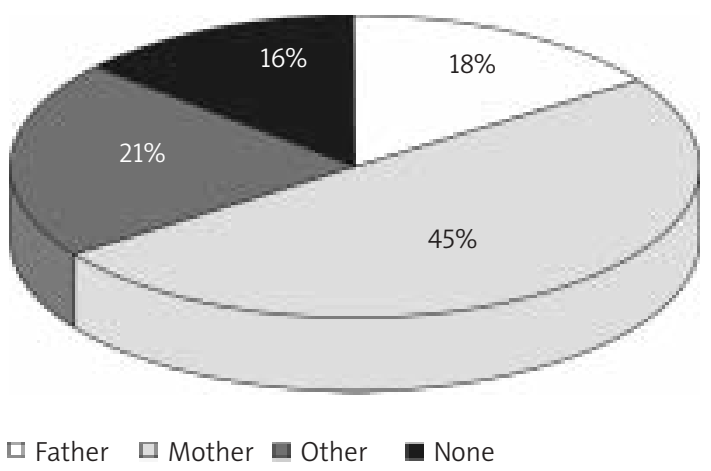

Figure 1. Family history of migraine in group A

Martelleti et al. [10, 14, 15]. These three recent studies showed an increased risk of migraine without aura associated with the TNF- $\alpha$ G308A polymorphism (Table IX).

These discordant results may be explained considering the significant differences among the allele frequencies of TNF gene variants in populations from different ethnic groups and hypothesizing the same linkage disequilibrium with the susceptibility genes of migraine without aura. In particular, the TNF- $\alpha-308 \mathrm{~A}$ allele is very rare in Asians (A/G 16/84\%) and Japanese (A/G 2/98\%) [18]. Additionally, gene-gene, as well as gene-environment interactions are likely, since migraine does not fit a simple Mendelian pattern but is a "multifactorial disease". This could in part explain why investigations of candidate susceptibility genes in case control group studies as well as linkage analyses 
Table VII. Correlation between genotypes and sex

\begin{tabular}{|c|c|c|c|c|c|}
\hline \multirow[t]{2}{*}{ SNPs } & \multirow[t]{2}{*}{ Genotypes } & \multicolumn{2}{|r|}{ Group A } & \multicolumn{2}{|c|}{ Group B } \\
\hline & & Boys & Girls & Boys & Girls \\
\hline \multirow[t]{3}{*}{ TNF-238 } & GG & $43(39.2)$ & $53(53.8)$ & $111(62.4)$ & $59(33.1)$ \\
\hline & $\mathrm{GA}+\mathrm{AA}$ & $4(4.1)$ & $3(2.9)$ & $7(3.9)$ & $1(0.6)$ \\
\hline & & & $p=0.171 \operatorname{Exp}(B)=0.395$ & $95 \%$ Cl 0.105-1.494 & \\
\hline \multirow[t]{3}{*}{ TNF-308 } & GG & $41(39.8)$ & $48(46.6)$ & $97(54.5)$ & $48(27.0)$ \\
\hline & $\mathrm{GA}+\mathrm{AA}$ & $5(4.8)$ & $9(8.7)$ & $21(11.8)$ & $12(6.7)$ \\
\hline & & & $p=0.278 \operatorname{Exp}(\mathrm{B})=1.457$ & $95 \% \mathrm{Cl} 0.738-2.875$ & \\
\hline \multirow[t]{3}{*}{ TNF-376 } & GG & $46(44.7)$ & $56(54.4)$ & $118(66.3)$ & $60(33.7)$ \\
\hline & GA & $0(0.0)$ & $1(0.9)$ & & \\
\hline & & & $p=1.000 \operatorname{Exp}(\mathrm{B}) 6.7 \mathrm{E}+09$ & & \\
\hline \multirow[t]{3}{*}{ TNF-857 } & $\mathrm{CC}$ & $29(28)$ & $35(36.1)$ & $74(41.6)$ & $40(22.5)$ \\
\hline & $\mathrm{CT}+\mathrm{TT}$ & $16(15.2)$ & $21(21.5)$ & $44(24.7)$ & $20(11.2)$ \\
\hline & & & $p=0.729 \operatorname{Exp}(\mathrm{B})=0.908$ & $95 \%$ Cl 0.528-1.563 & \\
\hline \multirow[t]{3}{*}{ TNF-1031 } & $\mathrm{TT}$ & $26(24.8)$ & $38(38.8)$ & $69(38.8)$ & $41(23.0)$ \\
\hline & $\mathrm{TC}+\mathrm{CC}$ & $19(18.5)$ & $18(17.9)$ & $49(27.5)$ & 19 (10.7) \\
\hline & & & $p=0.128 \operatorname{Exp}(\mathrm{B})=0.656$ & $95 \%$ Cl 0.382-1.129 & \\
\hline \multirow[t]{3}{*}{ TNF- $\beta$} & GG & $3(2.9)$ & $1(0.9)$ & $7(3.9)$ & $3(1.7)$ \\
\hline & $\mathrm{GA}+\mathrm{AA}$ & $42(41.8)$ & $55(54.4)$ & $111(62.4)$ & $57(32.0)$ \\
\hline & & & $p=0.093 \operatorname{Exp}(B)=2.943$ & $95 \%$ Cl 0.835-10.371 & \\
\hline
\end{tabular}

Table VIII. The distribution of TNF polymorphisms with the presence of family history of migraine in patients

\begin{tabular}{|c|c|c|c|c|}
\hline \multirow[t]{2}{*}{ SNPs } & \multirow[t]{2}{*}{ Genotypes } & \multicolumn{3}{|c|}{ Positive family history of migraine } \\
\hline & & Father (\%) & Mother (\%) & Brother-sister (\%) \\
\hline \multirow[t]{3}{*}{ TNF-238 } & GG & 8.2 & 28.4 & 3 \\
\hline & $\mathrm{GA}+\mathrm{AA}$ & 0.7 & 1.5 & 0 \\
\hline & & & NS & \\
\hline \multirow[t]{3}{*}{ TNF-308 } & GG & 8.2 & 25.4 & 2.2 \\
\hline & $\mathrm{GA}+\mathrm{AA}$ & 0.7 & 4.5 & 0.7 \\
\hline & & & NS & \\
\hline \multirow[t]{3}{*}{ TNF-376 } & GG & 9 & 29.9 & 3.0 \\
\hline & GA & 0 & 0 & 0 \\
\hline & & & NS & \\
\hline \multirow[t]{3}{*}{ TNF-857 } & CC & 7.5 & 14.9 & 0 \\
\hline & $\mathrm{CT}+\mathrm{TT}$ & 1.5 & 14.9 & 3.0 \\
\hline & & & NS & \\
\hline \multirow[t]{3}{*}{ TNF-1031 } & TT & 6.7 & 22.4 & 3 \\
\hline & $\mathrm{TC}+\mathrm{CC}$ & 2.2 & 7.5 & 0 \\
\hline & & & NS & \\
\hline \multirow[t]{3}{*}{ TNF- $\beta$} & GG & 10 & 3.0 & 0.7 \\
\hline & $\mathrm{GA}+\mathrm{AA}$ & 8.9 & 26.9 & 2.2 \\
\hline & & & NS & \\
\hline
\end{tabular}


Table IX. Results of different studies

\begin{tabular}{|c|c|c|c|}
\hline Study & SNP & Origin & Results \\
\hline \multicolumn{4}{|c|}{ Tumour necrosis factor (TNF)- $\alpha$} \\
\hline Rainero et al. (2004) & $-G 308 A$ & Italian (299/306) & Significant association $p \leq 0.001$ for $\mathrm{MO}$ \\
\hline Mazaheri et al. (2006) & $-G 308 A$ & Iranian (221/183) & Significant association $p \leq 0.001$ for $\mathrm{MO}$ \\
\hline Trabace et al. (2002) & $-G 308 A$ & Italian (79/101) & No association $p \geq 0.05 \mathrm{MA}$ \\
\hline Asuni et al. (2009) & $-G 308 A$ & Sardinian & No association $p \geq 0.05$ \\
\hline \multirow[t]{5}{*}{ Our study } & $-238 \mathrm{G} / \mathrm{A}$ & Greek (103/178) & No association $p \geq 0.05$ \\
\hline & $-308 \mathrm{G} / \mathrm{A}$ & Greek (103/178) & No association $p \geq 0.05$ \\
\hline & $376 \mathrm{~A} / \mathrm{G}$ & Greek (103/178) & No association $p \geq 0.05$ \\
\hline & $-857 \mathrm{C} / \mathrm{T}$ & Greek (103/178) & No association $p \geq 0.05$ \\
\hline & $-1031 T / C$ & Greek (103/178) & No association $p \geq 0.05$ \\
\hline \multicolumn{4}{|c|}{ Tumour necrosis factor (TNF)- $\beta$} \\
\hline Trabace et al. (2002) & TNF- $\beta$ & Italian (79/101) & Significant association $p \leq 0.05$ for $\mathrm{MO}$ \\
\hline Asuni et al. (2009) & TNF- $\beta$ & Sardinian (219/278) & Significant association $p \leq 0.05$ \\
\hline Martelleti et al. (2000) & TNF- $\beta$ & Italian (77/1010) & Significant association $p \leq 0.05$ \\
\hline Lee KA & LTA-294T/C & Korean (439/382) & Significant association $p \leq 0.05$ \\
\hline Our study & TNF- $\beta$ & Greek (103/178) & No association $p \geq 0.05$ \\
\hline
\end{tabular}

have at times shown variable results and attempts at independent replication have failed [14, 18].

Additional analyses could focus on clinical profiles, including symptoms, triggers, and successful treatments, thus providing a more comprehensive depiction of interactions between the various components of the disorder $[10,14,16]$. The severity of migraine symptoms, such as the recurrence and duration of attacks and the age at onset of disease, are variable among patients, thus rendering difficult the selection of the best population in which to investigate the genetic load.

Complicating the issue is the likelihood that many genetic variants may provide a modest yet significant contribution to an individual's migraine susceptibility. Moreover, there might be a genetic linkage between TNF polymorphisms and other genes involved in the immune response that increases the susceptibility of patients to development of migraine without aura.

Nevertheless, due to the complex polygenic nature of migraine, the search for migraine susceptibility genes will remain challenging. Also, the effective treatment options for migraine sufferers are limited. Thus, with greater knowledge of the genes and multiple gene profiles involved in migraine susceptibility, future applications may include individual genetic susceptibility profiling and personally tailored pharmacogenetics in order to abort attacks and control the disorder.

\section{References}

1. Estevez M, Gardner KI. Update on the genetics of migraine. Hum Genet 2004; 114: 225-35.

2. Moskowitz MA. Pathophysiology of headache-past and present. Headache 2007; 47 (Suppl 1): S58-63.

3. Mulder EJ, Van Baal C, Gaist D, et al. Genetic and environmental influences on migraine: a twin study across six countries. Twin Res 2003; 6: 422-31.

4. Colson NJ, Fernandez F, Lea RA, Griffiths IR. The search for migraine genes: an overview of current knowledge. Cell Mol Life Sci 2007; 64: 331-44.

5. Lee KA, Jang SY, Sohn KM, et al. Association between a polymorphism in the Lymphotoxin-a promoter region and migraine. Headache 2007; 47: 1056-62.

6. Lisi V, Garbo G, Micciche F, et al. Genetic risk factors in primary paediatric versus adult headache: complexities and problematics. J Headache Pain 2005; 6: 179-81.

7. Nair U, Bartsch H. Metabolic polymorphisms as susceptibility markers for lung and oral cavity. IARC Sci Publ 2001; 154: 271-90.

8. Howell WM, Turner SJ, Collins A, Bateman AC, Theaker JM. Influence of TNFalpha and LTalpha single nucleotide polymorphisms on susceptibility to and prognosis in cutaneous malignant melanoma in the British population. Eur J Immunogenet 2002; 29: 17-23.

9. Montagna P. The primary headaches: genetics, epigenetics and a behavioural genetic model. J Headache Pain 2008; 9: 57-69.

10. Trabace S, Brioli G, Lulli P, et al. Tumor necrosis factor gene polymorphism in migraine. Headache 2002; 42: 341-5.

11. Rzymski P. Tumor necrosis factor alpha receptors p55 and p75 and ovarian cancer - state-of-the-art research and clinical implications. Arch Med Sci 2005; 1: 3-7.

12. Asuni C, Stochino ME, Cherchi A, et al. Migraine and tumour necrosis factor gene polymorphism. J Neurol 2009; 256: 194-7. 
13. Perini F, D’Andrea G, Galloni E, et al. Plasma cytokine levels in migraineurs and controls. Headache 2005; 45: 926-31.

14. Rainero I, Grimaldi LM, Salani G, et al. Association between the tumor necrosis factor-alpha $-308 \mathrm{G} / \mathrm{A}$ gene polymorphism and migraine. Neurology 2004; 62: 141-3.

15. Martelletti P, Brioli G, Lulli P, Morellini M, Giacovazzo M, Trabace S. Tumor necrosis factor B gene polymorphism contributes to susceptibility to migraine without aura. Jead Pain 2000; 1: 119-22.

16. Mazaheri S, Hajilooi M, Rafiei A. The G-308A promoter variant of the tumor necrosis factor-alpha gene is associated with migraine without aura. J Neurol 2006; 253: 1589-93.

17. Headache Classification Committee of The International Headache Society. Classification and diagnostic criteria for headache disorders, cranial neuralgias and facial pain, 2nd edition. Cephalalgia 2004; 24 (Suppl 1): 1-160.

18. Shinohara Y, Ezura Y, Iwasaki H, et al. Three TNFalpha single nucleotide polymorphisms in the Japanese population. Ann Hum Biol 2002; 29: 579-83. 